\title{
The Role of Couple Compatibility as Social Capacity in Sustainable Community
}

\author{
Yasha Taheri Khameneh, Amin Aghakhani Morad, Javad Hami \\ ${ }^{I}$ Department of social science, M.Sc. in women studies, Islamic Azad University, Rudehen, Iran \\ ${ }^{2}$ Department of urban planning, Science and Research branch, Islamic Azad University, Boroujerd, Iran \\ ${ }^{3}$ Department of social science, M.Sc. in women studies, Islamic Azad University, Rudehen, Iran
}

\begin{abstract}
Marital adjustment denotes emotional stability, intellectual efficiency and social effectiveness people. Marriage is the key to whole some adjustment involvement and satisfaction. Marriage is our most common life style. One definition of adjustment is adaptation behavior that permits us to meet the demand of the environment. Also defined as a response to stress.

Aim of study investigated the relationship of emotional and social adjustment with marital satisfaction. This research is applied and the research method is "descriptive - analytical". The method of data collected is field and questionnaire. Therefore were used 180 questionnaires. Also, was used "SPSS" method for analyzing data also, was used "SPENIER \& ENRICH" questionnaire. On the other hand, case study, couple of ROZBEH consultant center. So, sample size is 100 couple.
\end{abstract}

Key word: Couple compatibility, social capital, community, Iran

\section{Introduction}

The family is a social unit that appears to be based on marriage (Selman, P. and Parker, J., 1997). In another definition, a family - in its narrowest meaning - is a unit that comprises a relationship, confirmed by society and more or less durable, between two people of different genders who form a common life, who have children and who raise them. This type of family has become a global phenomenon that is found in all types of societies (Senge, P., 1990) and which meets needs common to all humanity. Due to the significant importance of the family, sociologists consider it as a social institution, even though its functions may vary from one society to another (Wackernagel, M., Rees, W., 1996). As a key institution, in order to protect social structure and stabilize social life, the family structured family system for more desirable performances (Bostan, 2007). This institution is the place for interaction of three types of relations: the parent-child, the blood (genealogical) and the marriage relation.

Therefore, the expression "family" covers an extensive range of structures, forms and duties which vary in any country and change further inside a unique society, based on social class, cultural influences and income levels (Tokar, B., 1987). Two aspects relating to the issue of the family have been considered: (1) structure and function of the family, including intra-relations of the members and mutual interaction inside the family; (2) changes occurring inside the family due to relations between interior and exterior factors (Fadavi A. 2010). Morgan considers family functions within the framework of behaviors related to family life and concepts such as gender, institution and food (Bernards, 1952, translated by Ghazian, 2005). Such an approach indicates the belief function, which in turn identifies activities necessary to various types of social groups. In the developed forms, this approach is discussed by Mordak through four main functions of the family - sexual, economic, educational and reproductive. As for the second viewpoint, changes in the family shall be considered as one of the most important issues of today's era, which has generated a series of changes in relations inside the family. These changes include those relating to family function, mutual actions among people, manner of marriage, relation of spouses, women's employment and the development of renovation theories as individuals reach their 50s and 60s (Swanson, L., 1992). As with innovation in developing societies, families have changed significantly due to immigration of villagers, urban development, education and relative freedom of women, etc. (Roseland, M., 1998). Such changes lead Parsons to address the family values contradiction theory (requirements of loyalty, sympathy, and mutual commitment) with respect to global family values. This approach has highlighted gaps between new and old generations, or traditional and modern families (Bagaruzi A. 2007).

Iranian society has experienced a series of changes in various aspects of the society and families. These changes are even tangible within the specific lifetimes of individuals. In sociology, a generation refers to a group of people who start or end the various stages of life at the same time as each other. In the first vision (pertaining to family structure and function), generational differences are completely natural. Changes in financial situations, decreasing death rates, decreasing numbers of children, increasing levels of education and 
complexity of the external world have all contributed to differences, including those that are intra-generational. According to the Dourkim theory, such differences result in changes in family structure and roles (Monadi, 2006). When these changes are considered through the perspective of institution analysis, it may be said that inside any institution, certain constituents tend to have more power. In any institution, some constituents may act against the institution as a whole with the aim of overturning the institution and implementing their own ideas, values and norms. In the case of significant contradictions between the institution and constituents, if the latter does have greater power the institution itself will experience crisis. In keeping with this theory, parents within a family act as the institution and the children behave as constituents (Schon, D., 1983).

Due to the aforementioned two approaches and the importance of balancing functions within the family and preventing its destruction, recognizing factors relevant to family foundation fortification is crucial. It should be mentioned that the health of family functions depends on the health of marriage relations, (one of the indices of mental health and continuance of marriage life), particularly the identical feelings, satisfaction and joy experienced by couples who are subjected to various individual and social factors, including but not limited to employment and levels of intimacy that vary across cultures. (Putnam, R., Leonardi, R., Nanetti, R., 1993). Zinn and Eitzen consider the marriage relation as a process during which a couple, by expressing their thoughts and sentiments through their behavior, try to move towards more complete understanding on all levels. Married life typically means exclusivity in certain aspects of the couple's life. Existence of understanding and compatibility between the couple requires the achievement of a common ideology. It seems that this type of understanding involves a form of repeated stabilization and confirmation of the codes, relation and roles relevant to the spouses, who enable them to express their feelings, cooperate in planning and decision-making and hopefully try to solve problems (Lemann, N., 1996). In various steps of the marriage life cycle, the couples consider the difference and level of intimacy needs of each other which greatly affect compatibility between the spouses. Therefore, it may be said that in successful marriages, exchange and satisfaction of the intimacy needs of the couple as expected result in consolidation of affectionate relations between them and further that the main principle in successful marriages is establishment of intimacy between the couple (same). Halford (2005) states that marriage intimacy refers to the existence of interaction between the spouses, while lack of intimacy is the agitation index in the marriage relation. In a family with positive marriage relations, members of the family share in solving each other's problems and fewer quarrels occur between them. (Lian\&Yusooff, 2009). Sanderson, C. A. and .Karetsky, K. H. (2002) found out that those who cared about the interpersonal intimacy paid more attention to the concerns of their spouse and were trying to support him/her sentimentally. Therefore, they acted more skillfully in solving their contradictions. Meanwhile, Greeff, A.P. and Malherb, H.L. (2001) observed a meaningful relation between sexual intimacy and marital adjustment of the spouses. Those spouses who have satisfactory marriage relations, handle their children warmly and supportively (Parke and Buriel, 1998). Furthermore, those parents who have improper marital adjustment indicate weak parental style are recognized as cold, ignorant and quarrelsome parents and act inadequately in establishing limits, defining functions and a correct structure for the family (Park and O’Neil, 2000).

Chronic and continuous contradictions between spouses have destructive effects on the family system and also the children have unsafe dependency under such conditions (Lian and Yusooff, 2009). In a study performed by Feldman, S. S., Wentzel, K.R, Weinberger, D.A. and Munson, J., 1990, on the spousal marital adjustment relation and its effect on the family functions, emotional- social compatibility and educational progress of the children, they understood that there is a meaningful relation between marriage relations and functions of the family, the self-control of the children and quality of the marriage relations. The results of the study performed in periodical- descriptive manner on 186 pregnant ladies (both employed and unemployed) by the trustee (Maclaren, W., 1996), titled "Marriage Satisfaction and Intimacy of Couples with Employed and Unemployed Pregnant Wives in the City of Ardabil", indicated that there is meaningful correlation between marriage satisfaction and scopes of intimacy, except for physical intimacy. Another study, performed by Heidari and Eghbal (2011), investigated the difficulty in arranging emotions, dependency styles and intimacy with marriage satisfaction in the couples of Fooladshahr of Ahwaz. The authors concluded that there is negative meaningful relation between the difficulty in emotional arrangement and marriage satisfaction and avoiding dependency style and marriage satisfaction, while there is a positive meaningful relation between the safe dependency style and marriage satisfaction of the couples, as well as intimacy and marriage satisfaction of the couples. Meanwhile, through a study, Besharat (2003) showed that those couples who have safe dependency, enjoy more dependency, trust, commitment and marriage satisfaction while those couples who have avoidance dependency and mutual style suffer from more problems in their marriage relationships.

\section{Problem Statement}

Contemporary family life has become a focus for public concern and academic debate in recent years. Research has been concerned with mapping the overall picture and examining particular aspects of the increasing diversity of family forms and household structures: lone motherhood, post-divorce families, step- 
families, cohabitation, non-heterosexual families, and so on (for example, Berthoud and Gershuny 2000; Bradshaw et al. 1999; Duncan and Edwards 1999; Ferri and Smith 1996, 1998; Haskey 1999; Maclean and Eekelaar 1997; McRae 1993; Office for National Statistics 1998; Ribbens McCarthy et al. 2002; Smart and Neale 1999; Weeks et al. 2001), and with measuring and comparing outcomes for children (see overview by Rodgers and Pryor 1998). For some analysts, there are assumptions about the relationship between families and social cohesion, with the 'breakdown' of traditional family forms regarded as bringing social fragmentation (for example, Davies 1993; Morgan 1995; Murray 1994). For others, changing family forms are regarded in a more positive light, as generating new forms of social allegiance emphasizing negotiated consensual intimate relationships and obligations (for example, Beck 1992; Beck and Beck-Gernsheim 1995, 2002; Finch and Mason 1993; Giddens 1992; Weeks 1995). For still others, this focus on change in family life - whether for good or for ill - is overplayed (for example, Crow 2002; Jamieson 1998). A key area of debate is thus the extent of continuity or change in family life (for example, Silva and Smart 1999).

\section{Families in Mainstream Understandings of Social Capital}

\section{Social Capacity Literature}

Families are often regarded as a wellspring of social capital generation or destruction. Some commentators centre families, treating them as the main focus of their arguments. Others, however, decentre families: they acknowledge families as a key source of social capital but then shift their focus elsewhere. In this section we highlight families. We lay out the arguments of some mainstream social capital theorists, who represent different approaches both to the nature of social capital and to the centered or decentred place of families within it.

\section{Social capital}

Ostrom (1993) notes that all forms of capital are created by spending time and effort in transformation and transaction activities. Physical capital is the stock of material resources that can be used to produce a flow of future income. The origin of physical capital is the process of spending time and other resources constructing tools, plants, facilities, and other material resources that can, in turn, be used in producing other products. Human capital is the acquired knowledge and skills that individuals bring to productive activity. Human capital is formed consciously through training and education and unconsciously through experience. The first significant appearance of the concept of social capital was in the work of Jacobs (1961), where she used it to describe a norm of social responsibility, a corresponding atmosphere of social trust and interconnecting networks of communication. Social capital is the shared knowledge, understandings, and patterns of interactions that a group of people bring to any productive activity (Coleman, 1988; Putnam et al., 1993).

Social capital refers to the organizations, structures and social relations which people build-up themselves, independently of the state or large corporations. It contributes to stronger community fabric, and, often as a by-product of other activities, builds bonds of information, trust, and inter-personal solidarity (Coleman, 1990).

The term social capital refers to features of social organization such as networks, norms, and trust that increase a society's productive potential (Putnam et al., 1993). Though largely neglected in discussions of public policy, Putnam argues that social capital substantially enhances returns to investments in physical and human capital. However, unlike conventional capital, social capital is a public good, i.e. it is not the private property of those who benefit from it. Thus, like other public goods, from clean air to safe streets, social capital tends to be under-provided by private agents. The ties, norms and trust that constitute social capital are most often created as a by-product of other social activities and then transferred from one social setting to another.

Social capital is created when individuals learn to trust one another so that they are able to make credible commitments and rely on generalized forms of reciprocity rather than on narrow sequences of specific quid pro quo relationships. Ostrom (1993) notes that the shared cognitive aspects of social capital help account for two unusual characteristics that differ from physical capital:

First, social capital does not wear out upon being used more and more... Using

social capital for an initial purpose creates mutual understandings and ways of

relating that can frequently be used to accomplish entirely different joint activities at much lower startup costs... Social capital that is well adapted to one broad set of joint activities may not be easily molded to activities that require vastly different patterns of expectation, authority, and distribution of reward and costs than used in the initial sets of activities.

Second, if unused, social capital deteriorates at a relatively rapid rate. Individuals who do not exercise their own skills can lose human capital relatively rapidly. When several individuals must all remember the same routine in the same manner, however, the probability that at least one of them forgets some aspect increases rapidly over time. Further, as time goes on, some individuals leave and others enter any social aggregation. If newcomers are not introduced to an established pattern of interaction as they enter (through job training, 
initiation, or any of the myriad other ways that social capital is passed from one generation to the next), social capital can dissipate through nonuse; no one is quite sure how they used to get a particular joint-activity done. Either the group has to pay some of the start-up costs all over again, or forego the joint advantages that they had achieved at an earlier time.

Social capital differs from other forms of capital in several significant ways, one of which is that it is not limited by material scarcity, meaning that its creative capacity is limited only by imagination. It thereby also suggests a route toward sustainability, by replacing the fundamentally illogical model of unlimited growth within a finite world, with one of unlimited development* which is not bound by the availability of material resources. However, social capital also has limitations that other forms of capital do not. It cannot be created instantly, and the very fact of trying to consciously create it or direct it can create resistance. People resist being instrumental zed for even the best of reasons. Social capital takes time to develop, and is inherently nontransferable (Flora and Flora, 1993). It is also fragile and subject to erosion not only by direct assault but more importantly, by neglect, if there are many or strong competing attractors for investment of emotional significance or time.

The modern conceptualization of social capital is associated with Coleman (1988), who describes it as the relations between individuals and groups. It can take several forms, some of which are mutually recognized bonds, channels of information, and norms and sanctions. In this sense social capital is related to the concept of social ecology discussed later (Bookchin, 1987). The value of the concept, for Coleman, lies in the fact that it identifies aspects of the social structure by their functions. "The function identified by the concept of "social capital' is the value of these aspects of the social structure to actors as resources that they can use to achieve their interests" (Coleman, 1988).

\section{Research Methodology}

This research is applied and the research method is "descriptive - analytical". The method of data collected is field and questionnaire. Therefore were used 180 questionnaires. Also, was used "SPSS" method for analyzing data (Ebrahimpour, 2014).also, was used "SPENIER \& ENRICH" questionnaire.

ENRICH is a 125-item questionnaire for married couples that examines communication, conflict resolution, role relationship, financial management, expectations, sexual relationship, personality compatibility, marital satisfaction, and other personal beliefs related to marriage. It was developed by University of Minnesota family psychologist David Olson, Ph.D., and colleagues as a method of assessing the health of married couple relationships and is now used by over 100,000 facilitators in the United States and worldwide.

In studies of couples who completed the questionnaire, Fowers and Olson found ENRICH could predict divorce with $85 \%$ accuracy. Results from discriminate analysis indicated that using the individual scores or couples' scores, happily married couples could be discriminated from unhappily married couples with $85-95 \%$ accuracy.

\subsection{Descriptive findings}

\section{Finding}

Table 1 shows descriptive indicators.

\begin{tabular}{|} 
Table 1: descriptive indicators \\
\begin{tabular}{|c|c|c|c|c|}
\hline Variance & Standard & Standard false & Average & Descriptive indicators \\
\hline 301.1 & 17.3 & 1.7 & 93.60 & Male ( satisfaction) \\
\hline 309.8 & 17.6 & 1.76 & 93.90 & Female (satisfaction) \\
\hline 300.2 & 17.3 & 1.73 & 93.89 & Male (compatibility) \\
\hline 402.5 & 20.0 & 2.00 & 98.24 & Female (compatibility \\
\hline
\end{tabular}
\end{tabular}

according above data, descriptive indicators between male and women is similar .

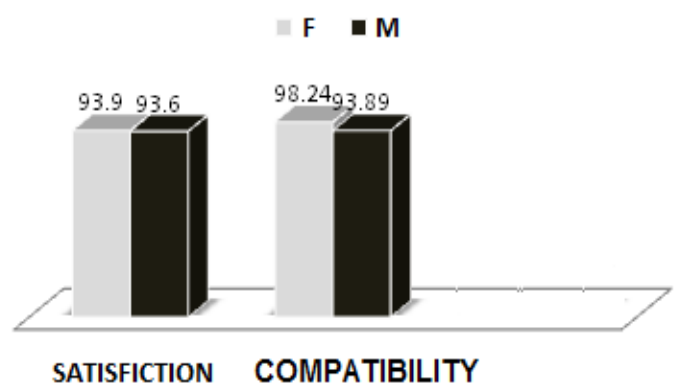

Figure 1: descriptive indicators 
In continue was used Pierson method in order to analyzing indicators. So, the relation between indicators is linier. Also, distribution is uniform. Therefore, was considered, pro-hypothesis by graph 1.

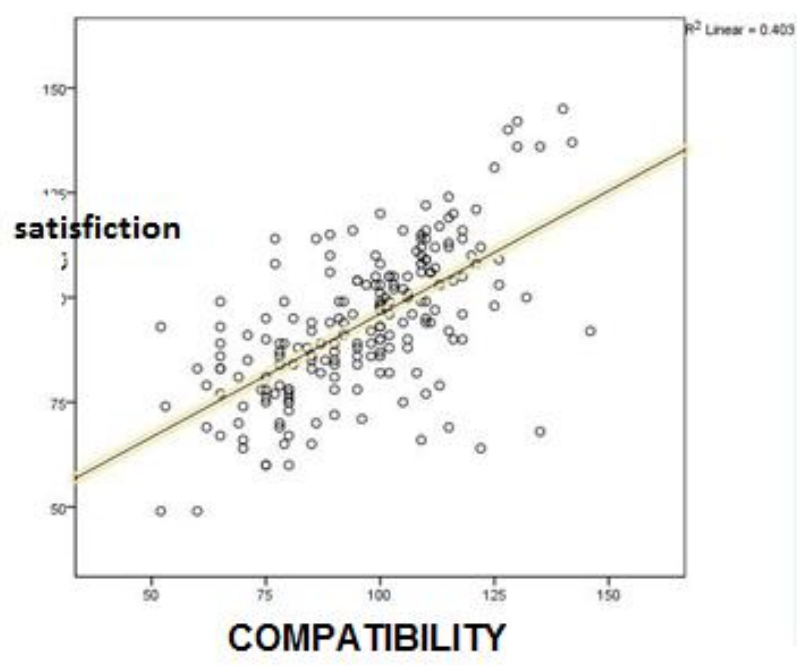

Graph 1: relation between indicators

\subsection{Pierson method}

In statistics, the Pearson product-moment correlation coefficient (/'prorsin/) (sometimes referred to as the PPMCC or PCC or Pearson's $r$ ) is a measure of the linear correlation (dependence) between two variables $X$ and $Y$, giving a value between +1 and -1 inclusive, where 1 is total positive correlation, 0 is no correlation, and -1 is total negative correlation. It is widely used in the sciences as a measure of the degree of linear dependence between two variables. It was developed by Karl Pearson from a related idea introduced by Francis Galton in the 1880 s.

Figur2: diagram of Pierson method
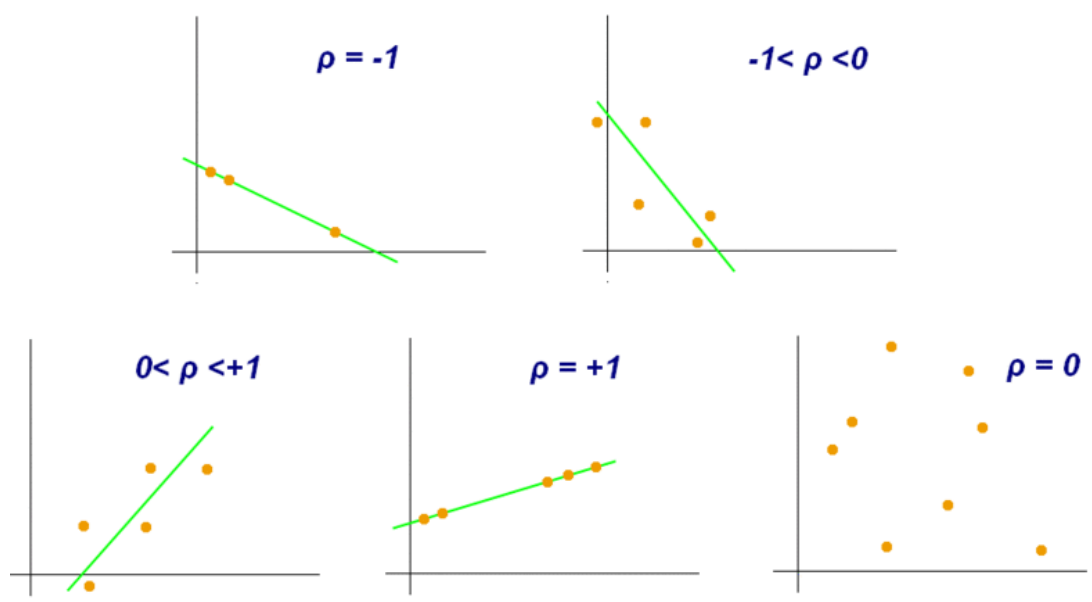

5.3. Hypothesis test

Based on results, there is positive relation between indicators. So the hypothesis is true (0.634). Table 2 shows detailed.

Table 2: positive relation

\begin{tabular}{|c|c|}
\hline \multicolumn{2}{|c|}{ COMPATIBILITY } \\
\hline Correlation between marital satisfaction & $\mathbf{0 . 6 3 4}$ \\
\hline Meaning & $\mathbf{0 . 0 0 1}$ \\
\hline Number & 200 \\
\hline
\end{tabular}




\section{Conclusion}

In response to the first question posed by this study, there was no observed meaningful difference between the family functions, level of marital adjustment and couples intimacy between the two groups of young and middle-aged spouses. With regard to the institutional analysis theory, it may be inferred that constituents (children or a young generation) follow the values and norms of the institution (parents) and there is no contradiction between the two constituent members with respect to the family functions, compatibility between the couples and their intimacy, or in case of such difference, it is not meaningful. On the other hand, it was observed that for the first time through human history perhaps, two adult generations of parents and children live with each other for a long time. When the oldest child gets married, then it is hoped that on average the father and mother continue to live with each other for 25 or 30 years. Yet when the children are 30-35 years of age, their father still retains responsibility and societal prestige. After marriage, second generations remain close to their parents geographically. It may be said the reason for no differences is the high level of relations between the two generations. Such relations, however, depend on the distance. Remote or telecommunicating relations can be added to the personal relations. The first generation is still in its middle-age. Therefore, it is involved, active and effective. The older people help younger ones in many aspects: finding jobs, buying property and furnishings for the recently married children, and helping the young mother so she does not lose the job she has recently acquired. This is a pattern that is especially observable in the city where the study took place, one which enjoys an ancient structure and where values and traditions are respected. It should be mentioned in responding to the second question that there is a meaningful relation between family functions, level of marital adjustment and couples intimacy and their education status. Meanwhile, a meaningful relation was observed between the performance subtests including: general function, roles, affective responsiveness, affective involvement and behavior control with the education of the spouses. In line with such findings, it has become clear that the couples with higher education see other purposes in marriage and forming a family, such as intimacy and commitment. According to the results of Dr. Monadi's study (2004), on the subject of the place of the imagination in the daily lives of the family, both the man and woman being of a similar class or background - mental and cultural though not economic - generates mutual speech and provides closeness in thought. Therefore it increases mutual recognition and life satisfaction for the couples. Eventually, education and not only knowledge itself is deemed as the factor for better understanding of the marriage life, but also acts as the relation channel between woman and man. Such findings are in line with the studies of Sells and Shawn (2002), Ghamarani and JafarTabatabaei (2006), Wilson and Smallwood (2008, quoted from Fadavi, 2010), Telsiz (1998), Azardanesh (2004) and Fadavi (2010). In response to the third question it can be said that there is no meaningful relation between the functions, level of marital adjustment and couples' intimacy and their marriage continuance. The findings documented above with the respect to the first question also apply here. It should be said in response to the fourth question that there is meaningful relation in significance 0.01 for 0.50 , between family function and marital adjustment for 0.68 and between marital adjustment and couples intimacy for 0.71. Also this finding is in line with the studies of Aleckranavi and Graham (2006), Sanderson and Kartesky (2002), Halford (2005), Motevalli, Ozgoli, Bakhtiari and Alavimajd (2009), Heidari and Eghbal (2011), Besharat

(2003), Zarepour and Asoudeh (2011), Azardanesh (2004), Parcket and Bouril (1998), Feldman et al. (1990), Park and O'Neil (2000). It is apparent that the services rendered by families have changed greatly over time in order to prepare and support family members as well reinforcing the capability of individuals to help themselves and others. To address short-term, medium-term and long-term needs, this study recommends supporting the concept of families, providing funding to encourage people to form families and accept spousal roles, striving for cultural and social promotion, and also encouraging the continuance of traditional values while moving from previous traditionsto the modern world.

\section{References}

[1]. Selman, P. and Parker, J., 1997. Citizenship, Civicness and Social Capital in Local Agenda 21. Local Environment 2(2).

[2]. Ebrahimpour, maryam (2014). Social safety's women in urban public space (Case study: Mashhad metropolitan) . American Journal of Engineering Research. Volume-03, Issue-08, pp-227-233

[3]. Senge, P., 1990. The Fifth Discipline, Double Day Currency, New York.

[4]. Wackernagel, M., Rees, W., 1996. Our Ecological Footprint: Reducing Human Impact on the Earth, New Society Publishers, Gabriola Island, BC.

[5]. Bostan H. 2007. Islam and Family Sociology.5th edition, Ghom: Howza\& University Research Center

[6]. Tokar, B., 1987. The Green Alternative, R. \& E. Miles, San Pedro.

[7]. Fadavi A. 2010. Effectiveness of the Emotional Intelligence Training on the Marriage Satisfaction and Marriage Contradictions of the Mothers who Have Elementary School Children in the City of Rasht. Gilan General Physicians Journal. No41-42.

[8]. Bernards J.1952. Translated by HosseinGhazian (2005) An Introduction to the Family Studies. Tehran: Ney press.

[9]. Swanson, L., 1992. Rural social infrastructure. In: Reid, J.N. (Ed.). Foundations of Rural Development Policy, Westview Press, Boulder, CO.

[10]. Roseland, M., 1998. Toward Sustainable Communities: Resources for Citizens and Their Governments, New Society Publishers, Gabriola Island, BC.

[11]. Schon, D., 1983. The Reflective Practitioner: How Professionals Think in Action, Basic Books, New York. 
[12]. Putnam, R., Leonardi, R., Nanetti, R., 1993. Making Democracy Work: Civic Traditions in Modern Italy, Princeton University Press, Princeton, NJ.

[13]. Lemann, N., 1996. Kicking in groups. Atlantic Monthly 277 (4), 22-26.

[14]. Lian CT, Yusooff F. 2009. The Effects of Family Functioning on Self-Esteem of Children. European Journal of Social Sciences, Vol 9(4).643-650.

[15]. Parke RD, Buriel R. 1998. Socialization in the Family .In N. Eisenberg (Ed), Handbook of Child Psychology (5the ed., vol. 3). New York: Wiley.

[16]. Park RD, O’Neil R. 1998. Social Relationships across Contexts: Family-Peer Linkages. In W. A. Collins \&Laursen, B. (Eds). Minnesota Symposium on Child Psychology (Vol.3).

[17]. Maclaren, V.W., 1996. Developing Indicators of Urban Sustainability: A Focus on the Canadian Experience. Intergovernmental Committee on Urban and Regional Research (ICURR) Press, Toronto.

[18]. Bagaruzi Dennis A. 2007.Improving the Long-Term Marriage Intimacy. Published by AlzahraUniversity.

[19]. Ostrom, E., 1993. Social Capital and Development Projects. Unpublished paper prepared for workshop "Social Capital and Economic Deveopment," American Academy of Arts and Sciences, Cambridge, MA, 30-31 July 1993.

[20]. Jacobs, J., 1961. The Death and Life of Great American Cities, Random House, New York.

[21]. Coleman, J.S., 1988. Social capital in the creation of human capital. American Journal of Sociology (supplement) 94, S95-S120.

[22]. Coleman, J.S., 1990. Foundations of Social Theory, Harvard University Press, Cambridge, MA.

[23]. Putnam, R., Leonardi, R., Nanetti, R., 1993. Making Democracy Work: Civic Traditions in Modern Italy, Princeton University Press, Princeton, NJ.

[24]. Flora, C.B., Flora, J.L., 1993. Entrepreneurial social infrastructure: a necessary ingredient. Annals of the American Academy of Political and Social Science 529, 48-58.

[25]. Bookchin, M., 1987. The Rise of Urbanization and the Decline of Citizenship, Sierra Club, San Francisco, CA. 